\title{
EXPECTED SEISMIC PERFORMANCE OF GRAVITY DAMS USING MACHINE LEARNING TECHNIQUES
}

\author{
Rocio L. Segura ${ }^{1}$, Jamie E. Padgett ${ }^{2}$ and Patrick Paultre ${ }^{3}$
}

(Submitted July 2020; Reviewed October 2020; Accepted November 2020)

\begin{abstract}
Methods for the seismic analysis of dams have improved extensively in the last several decades. Advanced numerical models have become more feasible and constitute the basis of improved procedures for design and assessment. A probabilistic framework is required to manage the various sources of uncertainty that may impact system performance and fragility analysis is a promising approach for depicting conditional probabilities of limit state exceedance under such uncertainties. However, the effect of model parameter variation on the seismic fragility analysis of structures with complex numerical models, such as dams, is frequently overlooked due to the costly and time-consuming revaluation of the numerical model. To improve the seismic assessment of such structures by jointly reducing the computational burden, this study proposes the implementation of a polynomial response surface metamodel to emulate the response of the system. The latter will be computationally and visually validated and used to predict the continuous relative maximum base sliding of the dam in order to build fragility functions and show the effect of modelling parameter variation. The resulting fragility functions are used to assess the seismic performance of the dam and formulate recommendations with respect to the model parameters. To establish admissible ranges of the model parameters in line with the current guidelines for seismic safety, load cases corresponding to return periods for the dam classification are used to attain target performance limit states.
\end{abstract}

\section{INTRODUCTION}

The consequences of dam failure can be substantial in terms of both casualties and economic and environmental damage. Thus, a dam must maintain its structural integrity in the face of different hazards and loading conditions that arise during construction, normal operations, and extreme environmental events. Therefore, dam safety is given the highest priority. Many dams were built more than 50 years ago [1]. Since that time, important advances in the methodologies for evaluating natural hazards have been made, causing the review and modification of design guidelines, and in some cases, the modification has been significant.

With the increasing knowledge of natural hazard evaluation, material behaviour, and structural analyses, a growing number of dams fail to meet the revised safety criteria that incorporate new and updated information. Based on this, dam engineering codes and guidelines have started to shift towards performancebased engineering design, which seeks to improve risk informed decision-making by incorporating methods with strong scientific and probabilistic bases. Consequently, the combination of ageing and its associated problems with new methods for estimating seismic loads, together with increasing societal demand to ensure higher levels of safety and the importance of the hydroelectric industry, has resulted in the need to review and upgrade the methods of safety analysis for dams.

Traditionally, dams were evaluated using deterministic analysis under an extreme event. Deterministic methods are often considered too conservative or even unsafe in some cases due to the use of extreme load cases with very low probabilities of occurrence in addition to neglecting different sources of uncertainty [2-4]. Thus, there is a need to move towards more refined methods to consider uncertainties inherent in the problem of dam safety assessment under extreme events. For these reasons, probabilistic-based methods have arisen as a useful tool in dam safety, and the results have been promising in recent studies [5-9]. However, the use of probabilistic methods for dams within a normative framework has not been well developed, although increasing research is being conducted. The most recent guidelines for the design and analysis of gravity dams include probabilistic notions for the assessment of these structures [10-13].

Within these probabilistic-based tools, fragility functions have become increasingly popular for the assessment of dams, particularly under seismic loads [14]. Frequently, these functions are generated using a single parameter to relate the level of shaking to the expected damage, rendering the analysis highly dependent on the selected seismic intensity measure (IM). To overcome this, the estimation of the fragility of the system can be potentially improved by increasing the number of predictor parameters. In this way, a more complete description of the ground motion properties can be obtained [15]. Consequently, the use of multiparameter models to predict the response of a certain structure is increasingly being used [14-16]. However, such methods often require a large number of nonlinear dynamic analyses of complex finite element models (FEMs). The substantial computational time may be reduced using machine learning techniques to develop surrogate or metamodels, which are engineering methods used when an outcome of interest cannot be easily directly evaluated, so a model of the outcome is used instead [17].

The joint application of numerical models, probabilistic approaches, and machine learning has gained considerable interest in the literature in recent years for engineering design and structural reliability [18-20]. This combination is justified by the significant randomness that characterizes not only the seismic events but also the structural system itself. Machine learning techniques within a seismic fragility framework have

\footnotetext{
1 Post-doc fellow, University of Sherbrooke, Sherbrooke, QC, Canada.

2 Professor, Rice University, Houston, TX, USA.

3 Corresponding Author, Professor, University of Sherbrooke, Sherbrooke, QC, Canada, Patrick.Paultre@USherbrooke.ca
} 
found recent applications in vulnerability assessments of buildings and bridges, among other structures [21-23] Similarly, for dam-type structures, an extensive comparison between machine-learning data-based predictive models for monitoring the dam behaviour can be found in Salazar et al (2015) [24], while Hariri-Ardebili and Pourkamali-Anaraki (2017) [25] and Hariri-Ardebili (2018) [26] applied machine learning techniques to perform reliability analyses applied to gravity dams against flooding, earthquakes, and ageing. More recently, Segura et al. (2020) [27] provided insight into viable metamodels for the seismic assessment of gravity dams for use in fragility analysis. However, there's still a need to further explore the correlation between the parameters defining the model configurations, including other relevant limit states for gravity dams, and the joint model parameter variations impact in the fragility analysis.

Thus, to improve and expedite the seismic assessment of gravity dams, this study proposes the use of a metamodel to emulate the seismic behaviour of the dam. The surrogate is built considering the modelling parameters (MP) in the numerical model and several seismic intensity measures to properly depict the seismic scenario likely to occur at the dam site. The latter is used to predict the continuous relative maximum base sliding of the dam to generate fragility functions. These fragility functions account for the effects of the variation in the parameters involved on the calculation of the response of the dam to enhance the accuracy of the fragility estimates. In addition, design parameter recommendations, that correspond to the modelling parameters explored, are formulated with respect to the return periods prescribed by safety guidelines. The proposed methodology is applied to a gravity dam located in north-eastern Canada.

\section{METAMODEL GENERATION}

Machine learning models are trained using data with specific features. The way in which the data are structured helps the models to learn and develop relationships between these features. A well-processed training set is required to build a robust model, which in turn generates accurate results [17].

Following traditional strategies specific for computer simulations [28], in this study, a metamodel was developed to approximate the continuous seismic response of the dam. The procedure used to generate the metamodel can be summarized as follows: (i) develop an experimental design matrix for the finite element simulations to generate the sample points representing the different configurations of the system, (ii) conduct finite element simulations for each row of the experimental matrix, and (iii) fit regression metamodels to the training dataset. The subsequent sections will detail these steps.

\section{Experimental Design Matrix}

To build a robust model, one must keep in mind the flow of operations involved in building a quality dataset. Moreover, to minimize the associated cost of running a dynamic nonlinear FEM while analysing an adequate number of loading conditions and structural system configurations, an appropriate experimental design method should be used. Loading and material parameters likely to affect the seismic response of the structure should be considered, and their associated ranges should be based on experimental data or values found in the literature.

In the context of this study, Latin Hypercube sampling (LHS) is adopted to generate the training dataset representing the different configurations of the system under study. This sampling technique was selected because of its ability to divide the desired range of values for each of the $m$ parameters into $n$ equiprobable intervals and then select a sample once from each interval to ensure that the set of samples reflects the entire range of the parameters [29].

The rows of this Latin Hypercube experimental design matrix $\mathbf{X}$ are then paired with a suite of $n$ ground motions with varying intensity measures. Hence, the dimensions of the original Latin Hypercube experimental design matrix are $n \times m$. The set of considered parameters was selected by taking into account the input parameters in the numerical model and random variables (RV) frequently considered for probabilistic analyses in the literature $[5,9,30]$.

Table 1 presents the modelling parameters that were considered as random variables in the analysis of the dam response and for which the uncertainty was properly included through the probability distribution function (PDF). All remaining input parameters were kept constant and represented by their best estimate values. For the studied dam, owing to the limited availability of material investigations, the probability distributions were defined using the empirical data of similar dams. The uniform distribution was used for all parameters except for damping, where a log-normal distribution was assumed [31] since it is the maximum entropy probability distribution when data are limited to an upper and lower bound.

\section{Finite Element Simulations}

In the context of this study, 250 samples of the FEM were generated with LHS as a trade-off between the available computational resources and time. The maximum relative sliding at the base was the output of interest, and it was computed from nonlinear simulations.

\section{Numerical Model}

A finite element model of the structure that considers the nonlinearities was developed to analyse the dynamic seismic response under vertical and horizontal ground motions. The case study dam includes 19 unkeyed monoliths, a maximum crest height of $78 \mathrm{~m}$, and a crest length of $300 \mathrm{~m}$. The width is $4.6 \mathrm{~m}$ at the top and $62 \mathrm{~m}$ at the base of the largest monolith, as shown in Figure 1(a). The dam rests on a foundation consisting mainly of anorthosite gabbro and granitic gneiss [32], which

Table 1: Modelling parameter PDFs.

\begin{tabular}{lcccc} 
Parameters & Designation & PDF & Distribution parameters \\
\hline Concrete-rock tensile strength (MPa) & CRT & Uniform & $\mathrm{L}=0.2$ & $\mathrm{U}=1.5$ \\
Concrete-concrete tensile strength (MPa) & CCT & Uniform & $\mathrm{L}=0.3$ & $\mathrm{U}=2.0$ \\
Concrete-rock cohesion (MPa) & CRC & Uniform & $\mathrm{L}=0.3$ & $\mathrm{U}=2.0$ \\
Concrete-concrete cohesion $(\mathrm{MPa})$ & $\mathrm{CCC}$ & Uniform & $\mathrm{L}=0.9$ & $\mathrm{U}=2.5$ \\
Concrete-rock angle of friction $\left({ }^{\circ}\right)$ & $\mathrm{CRF}$ & Uniform & $\mathrm{L}=42$ & $\mathrm{U}=55$ \\
Concrete-concrete angle of friction $\left({ }^{\circ}\right)$ & $\mathrm{CCF}$ & Uniform & $\mathrm{L}=42$ & $\mathrm{U}=55$ \\
Drain efficiency $(\%)$ & $\mathrm{DR}$ & Uniform & $\mathrm{L}=0.0$ & $\mathrm{U}=66$ \\
Concrete damping $(\%)$ & $\mathrm{CD}$ & Log-Normal & $\lambda=-2.99 \quad \zeta=0.35$ \\
\hline
\end{tabular}


corresponds to hard rock (VS30 > $1500 \mathrm{~m} / \mathrm{s}$ ). Due to its welldocumented dynamic behaviour, forced vibration test results were used to calibrate the dynamic properties of the numerical dam model [32].

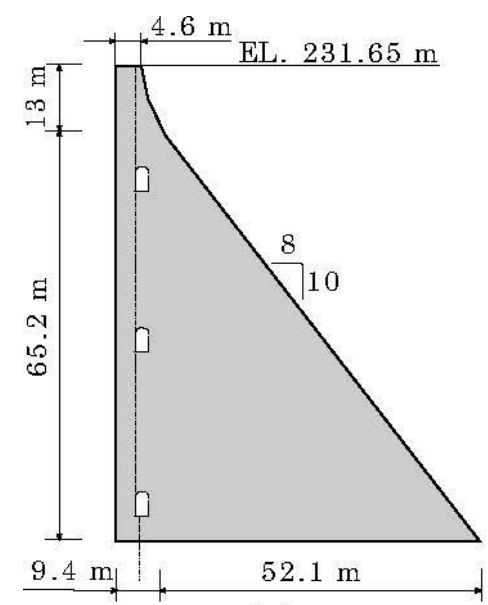

(a)



Figure 1: (a) Cross section and (b) FEM scheme.

Due to the presence of contraction joints, the interaction between the blocks of the dam is not significant enough to justify the realization of a complex 3D model. Hence, the tallest monolith of the dam was considered representative of the system. A numerical model was developed following the recommendations of Segura et al. (2019) [9] and the United States Bureau of Reclamation (USBR) [33]. The dam-reservoirfoundation (DRF) system was modelled using the computer software LS-Dyna, and the different model features are shown in Figure 1(b).

The reservoir was modelled with compressible fluid elements, while the concrete body of the dam and the rock foundation were modelled with linear elastic materials. The validation of the dynamic characteristics was based on the fundamental period of the system and global damping. Because of the type of element used to model the reservoir in the LS-Dyna model, a modal analysis could not be performed. Therefore, a free vibration test was simulated to estimate the fundamental period and the damping of the system. Considering gravity loads only, a force was applied at the crest of the block in the upstreamdownstream direction, and then suddenly withdrawn. The recorded horizontal displacement time series of a node at the crest of the block was then used to estimate the fundamental period of the system through the calculation of the Fourier spectrum and the global damping was approximated using the logarithmic decrement. Further details of the modeling assumptions and validation of the numerical model can be found in Segura et al. (2019) [9] and Bernier et al. (2016) [44].
By modifying the properties of the dam and the foundation materials, the fundamental period and total damping of the DRF system were $0.25 \mathrm{~s}$ and $2.64 \%$ respectively, which matches the results from in situ forced vibration tests [32]. Only one loading case is considered to analyse the seismic response of the case study structure, which includes the self-weight of the block, hydrostatic and hydrodynamic loads exerted by the reservoir on the block, uplift pressures at the concrete-rock contact, and horizontal and vertical seismic loads.

\section{Seismic Scenario Definition}

To proceed with the seismic assessment of the DRF system, a representative set of ground motion time series (GMTS) which properly accounts for the aleatory uncertainty is necessary [34]. Although eastern Canada is located in a stable zone, the occurrence of several major earthquakes in the southeast of the country led to the consideration of this area as a moderate seismic zone.

Using the computer software OpenQuake, a probabilistic seismic hazard analysis (PSHA) was performed at the dam site to characterize target earthquake scenarios at various intensity levels. The most recent hazard model for the south-eastern quadrant, on which the seismic provisions of the 2015 National Building Code of Canada (NBCC) [35] are based, was considered for this study. Empirical ground motion models were provided in the form of lookup tables (based on Atkinson and Adams (2013) [36]) were used together with the considered sources. The hazard levels were defined in terms of spectral acceleration at the fundamental period of the structure $\left[\mathrm{Sa}\left(\mathrm{T}_{1}\right)\right]$ to conveniently cover return periods up to 30000 years.

To select a representative set of ground motion time series, the generalized conditional intensity measure (GCIM) approach [37] was adopted. The purpose of using the GCIM approach is to include the most influential seismic intensity measures with respect to the structural response. To this end, the vertical spectral acceleration $\mathrm{Sav}$ was included in the analysis because of its influence in heavy structures of this type as well as the peak ground velocity (PGV) given its capacity to correlate with the output of interest while being a structureindependent ground-motion scalar IM [38]. Consequently, the

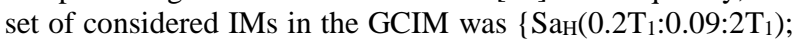
$\left.\operatorname{Sav}\left(0.2 \mathrm{~T}_{1}: 0.09: 2 \mathrm{~T}_{1}\right) ; \mathrm{PGV}\right\}$, leading to a total of $41 \mathrm{IMs}$ to be considered in addition to the conditioning $\mathrm{IM}, \mathrm{Sa}\left(\mathrm{T}_{1}\right)$. It should be noted that the range of periods considered for the horizontal and vertical spectral accelerations was determined as proposed by Baker [39].

The computed GCIM distribution was then used to select 250 ground motion records to be paired with the rows of the experimental design matrix. The records were selected from the PEER NGA-West2 database [40] owing to the limited availability of strong ground-motion records in the PEER NGA-East database [41]. Additional details on the PSHA, the record selection procedure and the distribution of intensity measures across the ground motion set can be found in Segura et al. (2018) [29] and Segura et al. (2020) [27].

\section{Surrogate Model}

For each row, $\mathbf{x}_{\mathbf{i}}$ of the experimental design matrix, one finite element simulation was conducted. The structural response considered herein was the maximum relative sliding $\delta_{\max }$. Therefore, a response vector $\mathbf{y}[250 \times 1]$ was produced as a result of the FEM simulation to train a regression metamodel. To reduce the computational expense, the surrogate acts as a 'curve fit' to the generated training dataset so that results may be predicted without recourse to the expensive simulation code.

The regression technique considered in this study is within an adaptive scheme, i.e., the functions in the metamodel can 
change according to the input data to reduce the burden of manual selection of the best demand and capacity predictors in the metamodel. To select the best predictors, the stepwise regression algorithm in MATLAB was used when fitting the metamodels. The algorithm starts with a constant term to predict the response. In the next step, one predictor is added to the model, and the performance of the model is evaluated based on the Bayesian information criterion (BIC). If the model performance improves, then the added term is kept; otherwise, it is removed, and this process is repeated until all proposed predictors are tested. Once the regression metamodel has been trained, the predictive capacities are evaluated based on crossvalidation (CV) goodness-of-fit estimates. Within this framework, a polynomial response surface of order 4 (PRS O4) was considered because it has been shown as one of the bestperforming metamodels for the seismic analysis of gravity dams [27].

\section{Polynomial Response Surface}

The polynomial response surface is an emerging technique that can provide a nuanced view of relationships between combinations of several predictor variables and an outcome variable [28]. In this study, it is employed to quantify the sliding response of gravity dams and used to assess the potential for reaching the sliding limit state. Traditionally, lower-order polynomials (up to second order) are used as metamodels in reliability problems, yet these functions may not be able to capture highly nonlinear behaviour. Regarding higher-order polynomials, even if these functions have higher predictive accuracy, they tend to overfit the data. Polynomials up to the 4th order were implemented to avoid overfitting issues, along with testing cross-validated goodness of fit measures.

The sparse polynomial response surface can be represented as:

$y=\boldsymbol{\theta}^{\top} g(\mathbf{X})+v$

where $y$ is the output of interest as a result of the finite element model simulation; $g$ is a column vector that includes explanatory functions such as logarithm and natural logarithm transformations, powers, and cross-products of powers of the predictors in $\mathbf{X}$ up to a predefined degree; $\boldsymbol{\theta}^{\top}$ is the row vector of model parameters, which are unknown constant coefficients; and $v$ is the model error due to the lack of fit of the surrogate model. In this study, in addition to the modelling parameters of Table 1, the set of predictors includes multivariate log-normally distributed seismic IMs extracted from the GMTS, such as horizontal spectral acceleration and velocity at the fundamental period, horizontal peak ground acceleration, velocity and displacement, vertical peak ground acceleration, spectrum intensity, Arias intensity, significant duration and earthquake angular frequency.

The resulting metamodel is a function of three model parameters and three seismic intensity measures, as can be seen from Eq. 2:

$\delta_{\text {max }}=19.75-1.11 \mathrm{DR}-25.46 \mathrm{PGA}_{\mathrm{V}}-10.96 \log (\mathrm{CRF})+$ $0.99 \log \left(\mathrm{I}_{\mathrm{A}}\right)+9.95 \log \left(\mathrm{PGA}_{\mathrm{V}}\right)-0.08 \log (\mathrm{CRC})^{3}-$ $0.38 \log \left(\mathrm{I}_{\mathrm{A}}\right)^{3}-1.56 \log (\mathrm{PGV})^{2}-0.40 \mathrm{DR} \log \left(\mathrm{I}_{\mathrm{A}}\right)+$ $0.11 \mathrm{PGA}_{\mathrm{V}} \log (\mathrm{CRC})^{3}+0.04 \log (\mathrm{CRF}) \log (\mathrm{CRC})^{3}-$ $0.11 \log \left(\mathrm{I}_{\mathrm{A}}\right)^{4}-0.04 \log \left(\mathrm{PGA}_{\mathrm{V}}\right) \log (\mathrm{CRC})^{3}+$ $0.009 \log (\mathrm{PGV})^{2} \log (\mathrm{CRC})^{3}$

where DR, CRC, and CRF are the drain efficiency, concreterock cohesion, and concrete-rock angle of friction, respectively, and, PGAv, $\mathrm{I}_{\mathrm{A}}$, and $\mathrm{PGV}$ are the peak ground acceleration in the vertical direction, Arias intensity, and peak ground velocity, respectively.

\section{Goodness-of-Fit}

To evaluate the prediction accuracy of the surrogate, global and local goodness-of fit estimators are calculated within a 5-fold cross-validation (5-CV) procedure [17]. In this procedure, the dataset is randomly divided into $k=5$ sets, and the surrogate is trained using $k-1$ sets, with the remaining set used as test data. This procedure is repeated 5 times; thus, $5-\mathrm{CV}$ provides an estimate of the predictive accuracy of the model for unknown data. Using a new fold as the test set, these estimators are obtained at each fold, and the average value of the five repetitions is used as the model goodness-of-fit. As such, the root mean square error (RMSE), relative maximum absolute error (RMAE), and coefficient of determination $\left(\mathrm{R}^{2}\right)$ corresponding to the PRS O4 are 0.321, 0.898, and 0.887, respectively.

To evaluate the surrogate lack of fit with the FEM simulations [Figure 2(a)], a normally distributed model error term $v$ with zero mean and standard deviation equal to the RMSE is added, as shown in Eqs. 3-4:

$\widehat{\delta_{\max }}=\delta_{\max }+v$

$v \sim \mathcal{N}\left(0,0.321^{2}\right)$

From Figure 2(b), it can be seen that the residual normal distribution error hypothesis is followed.
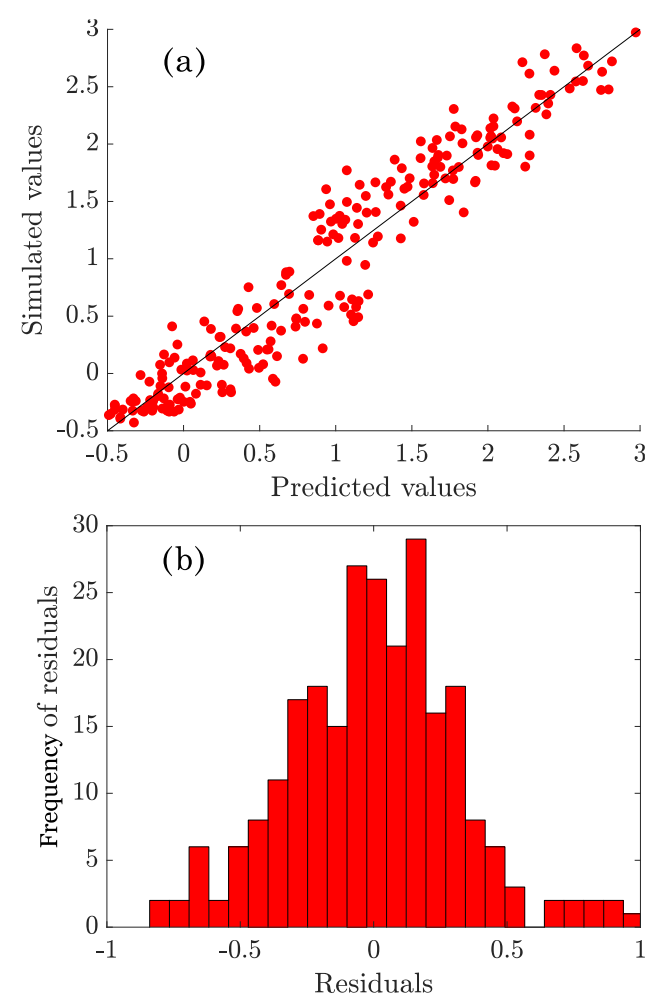

Figure 2: Whole training set: (a) predicted vs. simulated values and (b) residual frequency.

\section{Damage Limit States}

The first step toward fragility analysis is the identification of the limit states that are relevant to the system performance. In recent years, typical damage modes that could lead to the potential collapse of dams after a seismic event have been identified, and seismic damage levels have been established. Preliminary analyses identified sliding as the critical failure mode for the case study dam [44], and other failure modes only occur after sliding has already been observed. As a result, a single limit state is considered in this study, that is, concrete-to- 
rock sliding at the base of the dam interface. Each limit state was characterized by the sliding damage states presented in Table 2.

Table 2: Sliding limit states.

\begin{tabular}{lc} 
Damage state & Base sliding $(\mathbf{m m})$ \\
\hline LS0 - Slight & 5 \\
LS1 - Moderate & 25 \\
LS2 - Extensive & 50 \\
LS3 - Complete & 150 \\
\hline
\end{tabular}

\section{Dimensionality Reduction and Failure Surface} Visualization

The goodness-of-fit estimators have shown the satisfactory performance of the PRS O4 to predict the seismic response of the dam. However, prior studies have suggested potential limitations of applying metamodels for approximating limit state functions when high-curvature failure surfaces might exist [16]. To this end, dam failure surfaces under seismic events need to be explored to validate the applicability of the metamodel.

As pointed out by Ghosh et al. (2013) [16], a common challenge in the literature is the lack of failure surface visualization tools for high-dimensional limit state functions. This problem is present in the adopted 6-dimensional metamodel for the case study dam. To address this obstacle, the dimensionality reduction method proposed by Hurtado (2012) [42] is adopted. This provides a simple yet powerful technique to visualize multidimensional problems in two-dimensional failure surfaces.

The main steps when applying the dimensionality reduction method in this study can be summarized as follows: (i) formulation of the limit state equations according to Eq. 4, where $\mathrm{LS}_{\mathrm{i}}$ is the considered damage state; (ii) determination of the design point vector at which the limit state function $L S f$ is minimum with the Hasofer and Lind algorithm [43]; (iii) computation of the vector $\mathbf{w}$ to the centre of mass of the failure domain from Eq. 5, where $\nabla \operatorname{LS} f\left(X^{*}\right)$ is the value of the gradient of the limit state function evaluated at the design point; (iv) selection of random vectors $\mathbf{x}_{R}$ in the sampling space and classifying them as 'exceedance' $\left[\operatorname{LS} f\left(\mathbf{x}_{\mathrm{R}}\right)<0\right]$ or ' $\neg$ exceedance' [ $\operatorname{LS} f\left(\mathbf{x}_{\mathrm{R}}\right)>0$ ], then calculating the norm of these vectors $\left(\mathrm{V}_{\mathrm{r}, 1}\right)$ and the cosine between $\mathbf{x}_{\mathrm{R}}$ and $\mathbf{w}\left(\mathrm{V}_{\mathrm{r}, 2}\right)$; and $(\mathrm{v})$ repetition of step (iv) within an LHS strategy to generate $10^{4}$ samples.

$L S f=L S_{i}-\widehat{\delta_{\max }}$

$\mathbf{w}=-\frac{\nabla L S f\left(\boldsymbol{X}^{*}\right)}{\left\|\nabla L S f\left(\boldsymbol{X}^{*}\right)\right\|}$

By plotting $\mathrm{Vr}, 1$ vs. $\mathrm{Vr}, 2$ while accounting for the exceedance/ᄀexceedance classification, a visualization of the low curvature multidimensional failure surface in two dimensions can be obtained, as displayed in Figure 3.

It should be noticed that there is an evident delimitation between these two classifications. Sigmoid functions $G(\mathrm{Vr}, 1)$ were fit to the data to attempt to describe the two domains in a parametric manner, as shown in Figure 3(e). However, even if the demarcation between the domains is clear, further studies must be conducted regarding the parametric definition of $\mathrm{G}(\mathrm{Vr}, 1)$ to better distinguish between the damage states. The main outcome of this analysis is that the developed multidimensional metamodel has been validated computationally and visually and could be then used to perform a seismic fragility analysis.

\section{SEISMIC FRAGILITY ANALYSIS}

Estimation of fragility functions using dynamic structural analysis has been proven to be an important step in a number of seismic assessment procedures and a reliable instrument to support rational risk-mitigation decision-making. To optimize the computational resources, the metamodel emulating the seismic behaviour of the dam will be used instead of the FEM for the fragility analysis.

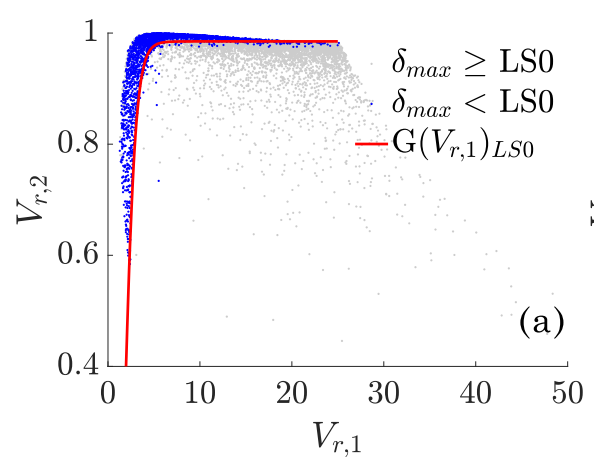

(a)

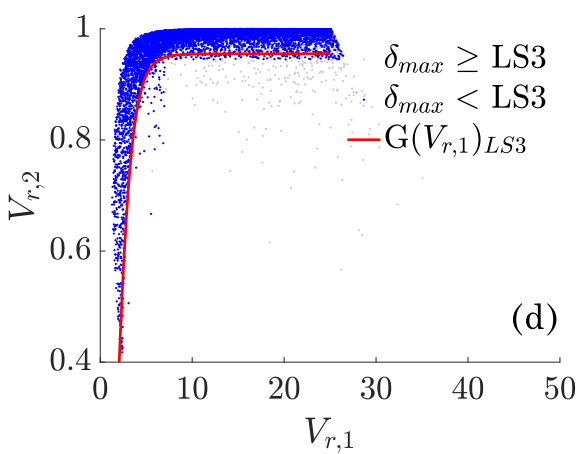

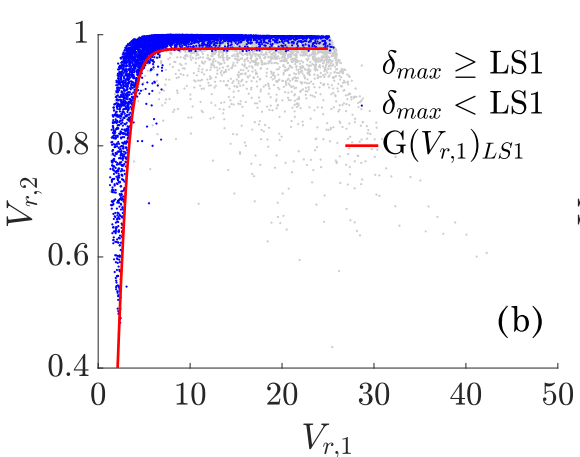

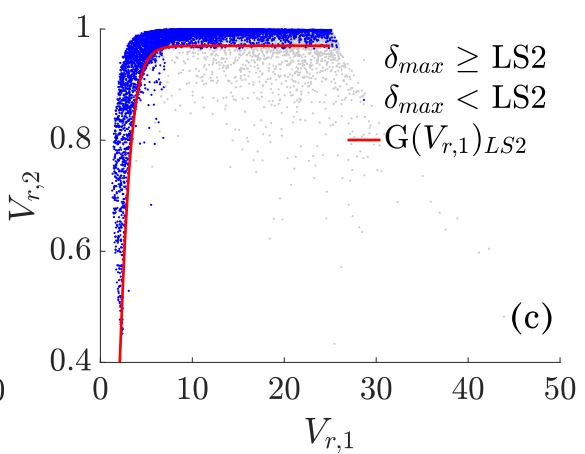

Figure 3: Multidimensional failure domain visualization. 


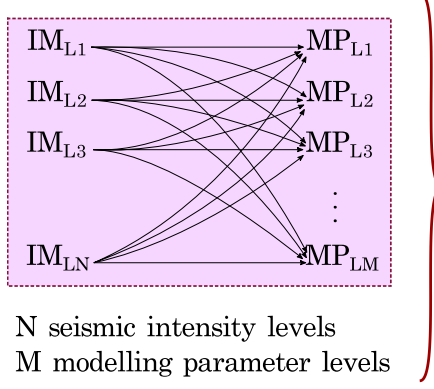

(a)

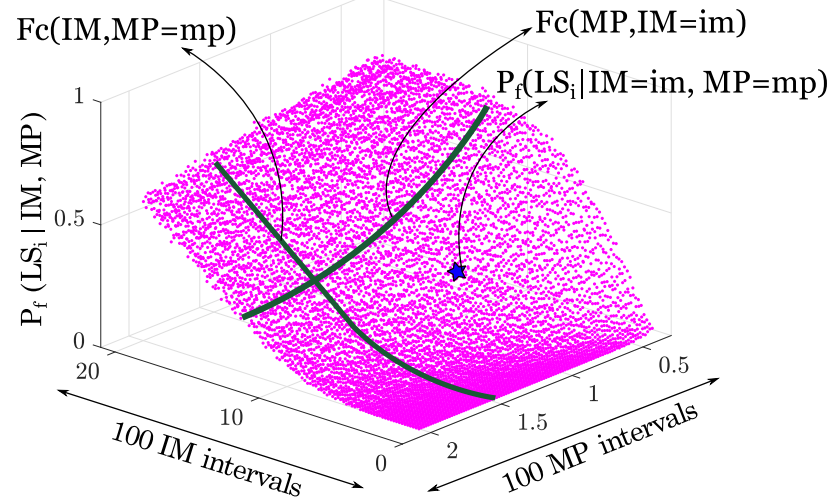

(b)

Figure 4: Point fragility estimate and fragility curve (Fc) generation as a function of two parameters.

\section{Metamodel Samples and Fragility Point Estimates}

Regarding the generation of samples where the surrogate will be evaluated to predict the dam's seismic response, independence between all modelling parameters was assumed to generate $5 \times 10^{5}$ samples with LHS.

The procedure to generate the point fragility estimates is displayed in Figure 4(a). A stratified sampling strategy based on multiple stripe analysis (MSA) [45] is adopted, where the two selected parameters are divided into $\mathrm{N}$ and $\mathrm{M}$ intensity levels. While one parameter is kept constant, the other is varied among the different levels, and its response is approximated with the surrogate. The point fragility estimate is calculated from a frequentist point of view as the number of samples with specific IM and MP intensity levels that exceed a determined limit state over the total number of samples generated with these specific MPs and IMs, according to Eq. 6,

$P_{f, i}=\frac{\sum \operatorname{Samples}\left(L S>L S_{i} \mid I M=i m, M P=m p\right)}{\sum \operatorname{Samples}(I M=i m, M P=m p)}$

where $\mathrm{LS}_{\mathrm{i}}$ indicates the damage state of interest in Table 2 and MP and IM are the modelling parameters and seismic IM involved in the prediction of the dam's seismic response with the metamodel, respectively.

The range of each considered parameter was divided into 100 intervals, so 100 samples were considered for each point estimate. As a result, $10^{4}$ fragility point estimates were generated for each limit state. While Figure 4 illustrates the process for scalar IM and MP, the approach is similar across a multi-dimensional space with vector IMs and MP.

\section{Fragility Functions}

Fragility analysis depicts the uncertainty in the safety margin with respect to specified hazard levels including design basis and review-level events [4]. Given that point fragility estimates are generated as a function of two parameters, it is possible to generate fragility curves as a function of one of these parameters, while the other one is kept constant and equal to a determined value, as shown in Figure 4(b). To estimate the functional form of the parametric fragility curves, normal, lognormal, and Weibull cumulative distribution functions (CDF) were fit to the data points. Following the recommendations of Baker [45], when using MSA, the maximum likelihood estimation (MLE) method was employed to fit the CDFs to the fragility point estimates and to approximate its parameters.

Two different cases were taken into account to generate fragility estimates as a function of two parameters. In the first case, as expected, correlation between the seismic IMs involved in the metamodel calculation was assumed to generate the samples. As a result, fragility estimates as a function of the PGV and each of the MPs involved in the prediction of the dam response were generated. In the second case, although less realistic, independence between the seismic IMs was considered to generate the metamodel's samples. Accordingly, point fragility estimates as a function of two seismic IMs were generated to consider more general cases where the seismic scenario is not well defined.

\section{EXPECTED SEISMIC PERFORMANCE}

Uncertainties prevail in the analysis of dam breaching consequences, particularly in the evaluation of the seismic hazard and the influence of variations in the dam material properties. Hence, it is important to consider various sources of uncertainties in dam safety assessment [1]. By formally including the modelling parameters and seismic loading uncertainty in the fragility analysis, it is possible to limit the ranges of these parameters to achieve a target performance when following safety guidelines.

\section{Earthquake Loading Conditions}

The usual, unusual, and extreme loading cases can be considered from the perspective of an event's annual exceedance probability. Critical loads such as seismic loads may be characterized on the basis of occurrence or exceedance probabilities. The actual probability of failure and the reserves in structural capacity can only be explicitly evaluated by using a probabilistic approach. Within this procedure, the risks are managed implicitly, often by application of a classification scheme that reflects the potential consequences of dam failure [46].

Table 3 lists the Canadian Dam Association (CDA) frequencybased target levels for consequence categories. This table is based on the concept of ensuring safety up to the physical limits of earthquake events, which the maximum credible earthquake MCE attempts to approximate.

\section{Table 3: CDA earthquakes' annual probability of exceedance.}

\begin{tabular}{lc} 
Dam class & Annual probability of exceedance \\
\hline Low & $1 / 100$ \\
Significant & Between $1 / 100$ and $1 / 1000$ \\
High & $1 / 2475$ \\
Very high & Between $1 / 2475$ and $1 / 10000$ \\
Extreme & $>1 / 10000$ or MCE \\
\hline
\end{tabular}


Traditional risk assessment methods have generally been successful in evaluating damage or consequences when considering seismic events defined with a particular return period (RP). As such, these traditional methods remain essential tools for dam design and safety management. In this study, the dam classification and return periods corresponding to Table 3 are used to assess the impact of the seismic event definition with respect to different RP in the fragility analysis and define the target seismic scenarios for the case study dam.

\section{Return Period Determination Effect on Fragility Analysis}

A structure is potentially exposed throughout its lifetime to all possibilities of occurrence of ground motion intensities at a given site, as characterized by the site-specific seismic hazard curve. Traditional vulnerability assessment methods develop fragility functions by using a single parameter to relate the level of shaking to the expected damage. Single-parameter demand models and fragility curves are highly dependent on the selected seismic intensity measure (IM), which consequently influences the robustness of predictions.

To overcome this, fragility functions to estimate the probability of exceeding a LS given PGV were generated to compare the variability of seismic fragility functions when the return periods are defined with single and multiple parameters. To this end, the values of the seismic IMs were bounded to cover the range of values corresponding to return periods from 100-15,000 years, as shown in Table 4 . All fragility curves were generated using the methodology illustrated in Figure 4(b). The uncertainty in the metamodel's parameters, not explicitly shown in the curve, was propagated in the analysis by sampling from the range of possible values, as depicted in Table 1 and Table 4.

\section{Table 4: Metamodel seismic IM considered range of} values.

\begin{tabular}{lc} 
Seismic IM & Range \\
\hline PGA $_{V}$ & $0.0-0.15 \mathrm{~g}$ \\
$\mathrm{PGV}$ & $0.0-15.0 \mathrm{~cm} / \mathrm{s}$ \\
$\mathrm{I}_{\mathrm{A}}$ & $0.0-1.5 \mathrm{~cm} / \mathrm{s}$ \\
\hline
\end{tabular}

\section{Uncorrelated Seismic IM Case}

To consider more general cases where the seismic scenario is not well-defined, fragility curves were generated where the correlation between the seismic IMs was neglected. The fragility point estimates were generated as a function of PGV and $\mathrm{I}_{\mathrm{A}}$, the two most influential seismic IMs. The uncertainty due to the modelling parameters and PGAv was propagated in

Table 5: Seismic IM correlation coefficients.

\begin{tabular}{lc} 
Seismic IM & Correlation \\
\hline IA-PGA $_{V}$ & 0.81 \\
PGA $_{V}$-PGV & 0.75 \\
$\mathrm{I}_{\mathrm{A}}-\mathrm{PGV}$ & 0.84 \\
\hline
\end{tabular}

the analysis by sampling these parameters with LHS according to their respective ranges of usable values. Figure 5(a)-(d) presents a boxplot of the point fragility estimates as a function of PGV. The central mark indicates the median of the $\mathrm{P}_{\mathrm{f}}$ values at each PGV intensity level, and the bottom and top edges of the box indicate the 25 th and 75 th percentiles, respectively. The whiskers extend to the most extreme data points that are not considered outliers. As can be seen, the variability in the fragility estimates increases with increasing PGV values and decreasing LS severity. To complement this analysis, Figure 5(e)-(h) presents fragility curves in red as a function of a single IM, PGV, and fragility curves as defined in Figure 4 for $\mathrm{PGV}$ and constant $\mathrm{I}_{\mathrm{A}}$ corresponding to different return periods ( $\mathrm{I}_{\mathrm{A}, \mathrm{RP}}$ ). It was observed that for most LSs, the obtained fragility curve is closer to the upper fragility curve resulting from the $\mathrm{I}_{\mathrm{A}}$ values corresponding to $\mathrm{RP}=10^{4}$ years, evidencing an estimation robustness that is highly dependent on the IM used to describe the seismic event. As an illustration, if for the MCE the corresponding is PGV $=15 \mathrm{~cm} / \mathrm{s}$, for LS3 the probability of exceedance is 0.06 for a seismic event characterized solely by PGV and 0.095 for a seismic event defined with PGV and $\mathrm{I}_{\mathrm{A}}$. Similarly, it should be noted that by using traditional singlevariate fragility functions where the seismic hazard is defined by only one IM, the fragility is overestimated for RP $<2475$ years and underestimated for RP $>10^{4}$ years.

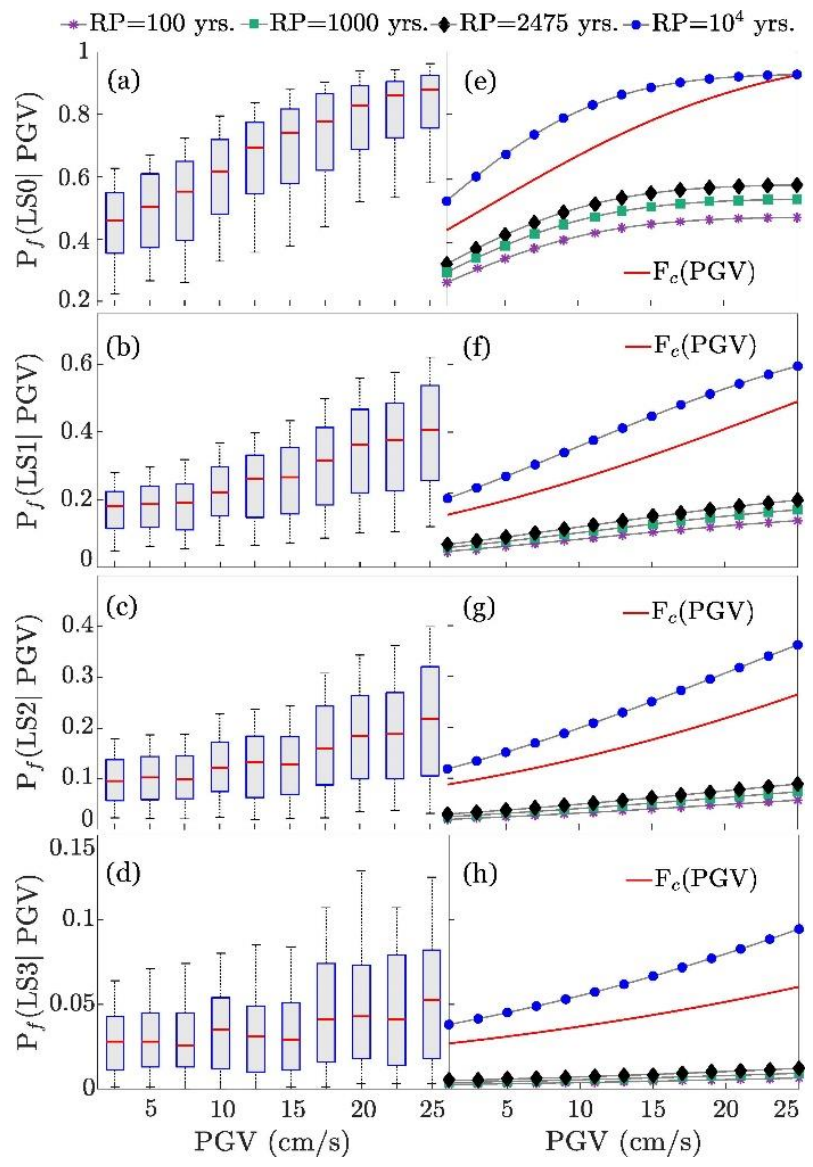

Figure 5: Fragility curves with uncorrelated seismic IMs Fc $\left(P G V, I_{A}=I_{A, R P}\right)$.

\section{Correlated Seismic IM Case}

For the case study dam, considering the PSHA and the characteristics of the seismic scenario for a specific site, a correlation between seismic parameters is to be expected. To explicitly consider this within the fragility derivation, the realization of these parameters must be sampled from a multivariate distribution with their respective correlation coefficients when referring to specific cases. The correlation coefficients for IMs of interest in the dam seismic performance assessment were obtained from the set of GMTS selected to train the metamodel and are displayed in Table 5.

Based on this, the samples of these parameters are taken from a joint log-normal distribution with their respective correlation coefficients, while the samples for the modelling parameters were obtained in the same manner as for the uncorrelated seismic IM case. Figure 6 presents fragility curves as a function of each of the modelling parameters that depict the probability of exceeding a LS for PGV corresponding to a given RP (PGVRP). It should be noted that even if the return periods are 
defined in terms of PGV, the influence of the other seismic IMs is considered in the seismic event definition by sampling from the joint log-normal distribution. Again, it can be seen that the variability in the fragility estimates $\left(\Delta \mathrm{P}_{\mathrm{f}}\right)$ increases for less severe LSs, and the modelling parameter variation impact is more evident for CRC, followed by DR and CRF.

\section{Modelling Parameter Recommendations for Desired Seismic Performance}

Many situations arise when performing risk analyses for dams where insufficient statistical information exists and models for calculating probabilities simply do not exist. To estimate the quantitative risk, it then becomes necessary to judge the likelihood of various events or conditions.

This can be done qualitatively considering expert engineering judgement regarding relevant event probabilities for the failure mode being discussed. Probabilities are then estimated or assigned using subjective, degree-of-belief probability methods [10].

A subjective probability estimate is the numerical value or range of values judged to be believable based upon the available evidence. Several authors [10,47-48] developed verbal mapping schemes that were adopted for most of the subjective probability estimates. Table 6 presents the verbal mapping scheme for risk analysis based on the USBR guidelines [10]. This approach is adopted herein.

From Table 3, Table 6, and Figure 6, modelling parameter recommendations can be formulated to achieve a desired target seismic performance. According to the CDA, the associated risk of the case study dam is classified as 'high', where the population at risk is located in the dam-breach inundation zone, the loss of life is estimated as 100 or fewer, and significant loss of critical fish or wildlife habitat and very high economic losses affecting important infrastructures and services is expected.
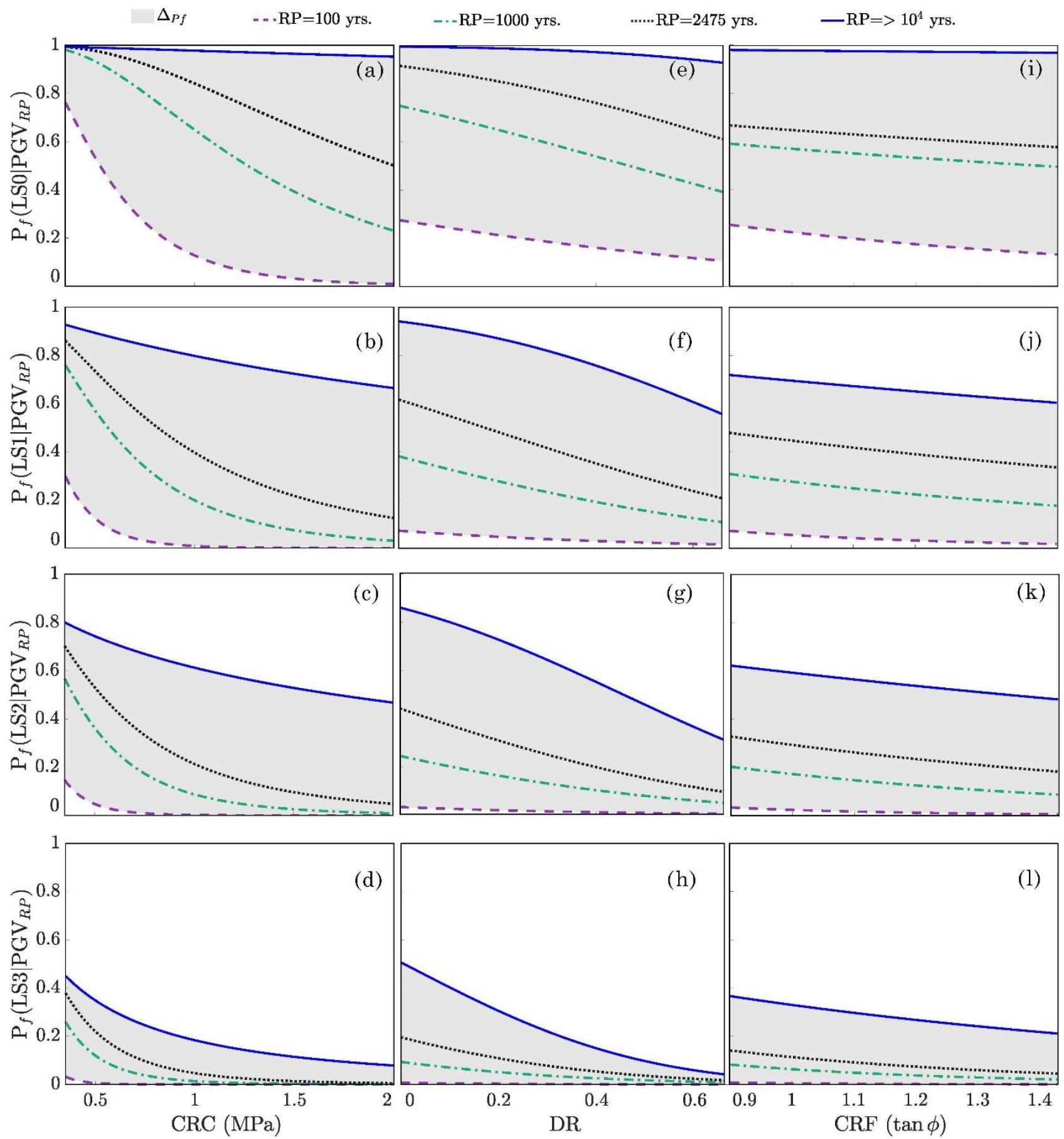

Figure 6: Fragility curves with correlated seismic IMs - Fc(MP, PGV=PGVRP). 
Table 6: Adopted verbal mapping scheme.

\begin{tabular}{lc} 
Descriptor & Assigned probability \\
\hline Virtually certain & 0.999 \\
Very likely & $>0.9$ and $<0.99$ \\
Likely & $>0.5$ and $<0.9$ \\
Neutral & 0.5 \\
Unlikely & $>0.1$ and $<0.5$ \\
Very Unlikely & $>0.01$ and $<0.1$ \\
Virtually Impossible & 0.001 \\
\hline
\end{tabular}

From Table 3, seismic events with an annual probability of exceedance of $1 / 2475$ are considered, and the assigned probability of exceedance given the event occurrence according to Table 6 is 'very unlikely'. From Figure 6, for the extensive and complete damage limit states $[(\mathrm{c})(\mathrm{g})(\mathrm{k})-(\mathrm{d})(\mathrm{h})(\mathrm{l})]$, the probability of exceedance $\mathrm{P}_{\mathrm{f}}$ is fixed at the lower bound equal to 0.1 . By intersecting the fragility curve corresponding to $\mathrm{RP}=2475$ years with this probability, modelling parameter ranges are defined. Table 7 presents the minimum values that should be followed to obtain $\mathrm{P}_{\mathrm{f}} \leq 0.1$ for LS2 and LS3. It should be observed that for the CRF parameter and the LS2 damage state, the probability of exceedance is always greater than 0.1 for the considered range of usable values [Figure $6(\mathrm{k})$ ], so no recommendation can be formulated. In other words, changing the CRF alone is not sufficient to achieve the targets and the joint variation of the MPs should be further explored.

Table 7: Modelling parameter recommendations.

\begin{tabular}{lcc}
$\begin{array}{l}\text { Modelling } \\
\text { parameters }\end{array}$ & $\begin{array}{c}\text { Extensive damage } \\
(\text { LS2 })\end{array}$ & $\begin{array}{c}\text { Complete damage } \\
(\text { LS3 })\end{array}$ \\
\hline CRC $(\mathrm{MPa})$ & $>1.45$ & $>0.75$ \\
$\mathrm{DR}(\%)$ & $>60$ & $>22$ \\
$\mathrm{CRF}\left({ }^{\circ}\right)$ & - & $>46$ \\
\hline
\end{tabular}

In the same manner, seismic regions can be established to define seismic scenarios that provide probabilities of exceeding LSs in line with current safety guidelines. For risk category III (dam-type structures) and total or partial structural collapse, the ASCE-7 (2016) guideline [46] proposes that the maximum probability of exceedance should be less than 0.06 for the MCE event. Accordingly, from the point fragility estimates determined as a function of two seismic IMs (uncorrelated case), $\mathrm{I}_{\mathrm{A}}-\mathrm{PGV}$ regions were defined so that the MCE samples falling in these regions provide $\mathrm{P}_{\mathrm{f}} \leq 0.06$ for each LS, as shown in Figure 7.

\section{CONCLUSIONS}

The main objective of this study was to apply a PRS metamodel to improve the seismic fragility assessment of gravity dams by generating fragility estimates as a function of several parameters and by properly identifying the seismic scenario with regard to current guidelines. The two cases analysed for the seismic assessment of the case study dam were (i) uncorrelated seismic IMs, where the point fragility estimates were generated as a function of uncorrelated $\mathrm{I}_{\mathrm{A}}$ and $\mathrm{PGV}$, and (ii) correlated seismic IMs, where the seismic properties were taken from a multivariate log-normal distribution and the point fragility estimates were generated as a function of PGV and each of the MPs. In both cases, fragility functions were developed for seismic return periods prescribed by the CDA guidelines, and design parameter recommendations were formulated based on expert engineering judgement regarding relevant event probabilities for the failure mode being discussed.

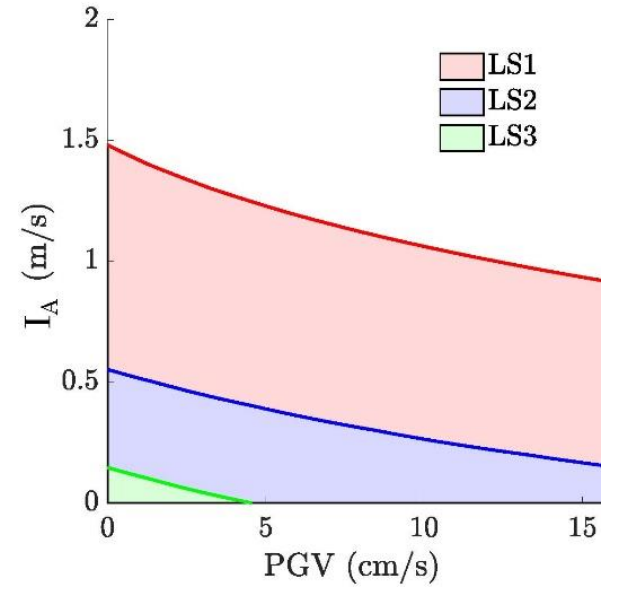

Figure 7: $I_{A}-P G V$ regions.

For the uncorrelated case, it should be mentioned that the proposed fragility functions allow the consideration of more general cases and a more efficient definition of the seismic demand. Further, fragility functions defining the seismic demand using a single IM may create a false sense that safety has been achieved under the ultimate seismic loadings. Nevertheless, it should be kept in mind that assuming two uncorrelated seismic IMs to generate the fragility estimates can lead to the consideration of seismic scenarios that are very unlikely to occur at the site of the structure during its lifetime. Similarly, the correlated case accounts for the variability of the modelling parameters in the fragility analysis together with the variability in the seismic hazard for a specific site. However, the main drawback of this approach is that it fails to include the simultaneous effect of these parameter variations and target design ranges are identified one parameter at a time.

Despite the shortcomings discussed above, it should be noted that machine learning techniques are promising alternatives when assessing the vulnerability of structures with computationally complex numerical models. Likewise, the use of surrogate models to conduct fragility assessments introduces flexibility into the analysis to explore the impacts of different parameters. It is believed that, in addition to the specifics of the present study, these emerging risk-informed approaches provide insight into the influence of parameter variation and uncertainties in seismic performance assessment of dams and may spur further interactions between engineers and decisionmakers seeking to operate in a risk-based context.

\section{ACKNOWLEDGEMENTS}

The authors acknowledge the financial support of MITACS, the Natural Sciences and Engineering Research Council of Canada (NSERC), and the Fonds de recherche du Quebec - Nature et technologies (FRQNT). Any opinions, findings, and conclusions or recommendations expressed in this paper are those of the authors and do not necessarily reflect the views of the sponsors.

\section{REFERENCES}

1 Schleiss AJ and Pougatsch H (2011). "Les Barrages, du Project a la mise en Service". Volume 17 of the Civil Engineering Treaty of the Swiss Federal Institute of Technology in Lausanne. Editor: PPUR Presses Polytechniques, ISBN 2880748313, 9782880748319. 714 pp. (in French)

2 Lave LB, Resendiz-Carrillo D and McMichael FC (1990). "Safety goals for high-hazard dams: are dams too safe?". Water Resources Research, 26: 1383-1391. https://doi.org/10.1029/WR026i007p01383 
3 Schultz MT, Gouldby BP, Simm JD and Wibowo JL (2010). "Beyond the Factor of Safety: Developing Fragility Curves to Characterize System Reliability". Technical Report ERDC SR-10-01, U.S. Army Corps of Engineers.

4 Tekie PB and Ellingwood BR (2001). "Fragility analysis of concrete gravity dams". Journal of Infrastructure Systems, 127(8): 41-48.

https://doi.org/10.1061/(ASCE)1076-0342(2001)7:2(41)

5 Kreuzer H and Léger P (2013). "The adjustable factor of safety: A reliability-based approach to assess the factor of safety for concrete dams". International Journal on Hydropower and Dams, 20(1): 67-80.

6 Westberg Wilde M and Johansson F (2013). "Probabilitybased guidelines for design and assessment of concrete dams". Safety, Reliability, Risk and Life-Cycle Performance of Structures \& Infrastructures, Deodatis EF, Ed., Taylor and Francis Group, 5187-5210.

7 Hariri-Ardebili M (2017). "Analytical failure probability model for generic gravity dam classes". Proceedings of the Institution of Mechanical Engineers, Part O: Journal of Risk and Reliability, 1-12. https://doi.org/10.1177/1748006X17712663

8 Cordier M and Léger P (2018). "Structural stability of gravity dams: a progressive assessment considering uncertainties in shear strength parameters". Georisk: Assessment and Management of Risk for Engineered Systems and Geohazards, 12(2): 109-122. https://doi.org/10.1080/17499518.2017.1395464

9 Segura RL, Bernier C, Durand C and Paultre P (2019). "Modelling and characterizing a concrete gravity dam for fragility analysis". Infrastructures, 4: 1-19. https://doi.org/10.3390/infrastructures4040062

10 USBR and USACE (2019). "Best Practices in Dam and Levee Safety Risk Analysis." Technical Report Version 4.1, U.S. Bureau of Reclamation and U.S. Army Corps of Engineer.

11 Kalinina A, Spada M, Marelli S, Burgherr P and Sudret B (2016). "Uncertainties in the Risk Assessment of Hydropower Dams: State-of-the-Art and Outlook". Technical Report RSUQ-2016-008, ETH Zurich.

12 FERC (2016). "Risk-informed Decision Making Guidelines". Technical Report Version 4.1, Federal Energy Regulatory Commission.

13 FEMA (2015). "Federal Guidelines for Dam Safety Risk Management". Report No. P-1025. Federal Guidelines for Dam Safety Risk Management, Federal Emergency Management Agency.

14 Hariri Ardebili M and Saouma V (2016). "Seismic fragility analysis of concrete dams: A state-of-the-art review". Engineering Structures, 128: 374-399. https://doi.org/10.1016/i.engstruct.2016.09.034

15 Alembagheri M (2018). "Investigating efficiency of vectorvalued intensity measures in seismic demand assessment of concrete dams". Advances in Civil Engineering, 12. https://doi.org/10.1155/2018/5675032

16 Ghosh J, Padgett JE and Duenas Osorio L (2013). "Surrogate modelling and failure surface visualization for efficient seismic vulnerability assessment of highway bridges". Probabilistic Engineering Mechanics, 34: 189199. https://doi.org/10.1016/j.probengmech.2013.09.003

17 Forrester AIJ, Sobester A and Keane AJ (2008). "Engineering Design via Surrogate Modelling: A Practical Guide". Chichester: Wiley.

$18 \mathrm{Yu}$ J, Qin X and Larsen O (2014). "Uncertainty analysis of flood inundation modelling using GLUE with surrogate models in stochastic sampling". Hydrological. Processes, 29(6): 1267-1279. https://doi.org/10.1002/hyp.10249

19 Sudret B (2012). "Meta-models for structural reliability and uncertainty quantification". Proceedings of the 5th AsianPacific Symposium on Structural Reliability (APSSRA 2012), Wuhan, China: Scientific Research Publishing. https://hal-enpc.archives-ouvertes.fr/hal00683179/document

20 Simpson W, Peplinski J, Koch P and Allen J (2001). "Metamodels for computer-based engineering design: Survey and recommendations". Engineering Computation, 17(Jul): 129-150. https://doi.org/10.1007/PL00007198

21 Mangalathu S and Jeon J-S (2018). "Stripe-based fragility analysis of multispan concrete bridge classes using machine learning techniques". Earthquake Engineering and Structural Dynamics, 48(11): 1238-1255. https://doi.org/10.1002/eqe.3183

22 Sichani E, Padgett JE and Bisadi V (2017). "Probabilistic seismic analysis of concrete dry cask structures". Structural Safety, 73(Jul): 87-98. https://doi.org/10.1016/j.strusafe.2018.03.001

23 Kameshwar S and Padgett JE (2014). "Multi-hazard risk assessment of highway bridges subjected to earthquake and hurricane hazards". Engineering Structures, 78(Nov): 154 166. https://doi.org/10.1016/j.engstruct.2014.05.016

24 Salazar F, Toledo MA, Onate T and Moran R (2015). "Data-based models for the prediction of dam behaviour: A review and some methodogical considerations". Archives of Computational Methods in Engineering, 24 (1): 1-21. https://doi.org/10.1007/s11831-015-9157-9

25 Hariri-Ardebili M and Pourkamali-Anaraki F (2017). "Simplified reliability analysis of multi hazard risk in gravity dams via machine learning techniques". Archives of Civil and Mechanical Engineering, 18(2): 592-610. https://doi.org/10.1016/j.acme.2017.09.003

26 Hariri-Ardebili M (2018). "MCS-based response surface metamodels and optimal design of experiments for gravity dams". Structure and Infrastructure Engineering, 14(12): $1641-1663$ https://doi.org/10.1080/15732479.2018.1469650

27 Segura RL, Padgett JE and Paultre P (2020). "Metamodelbased seismic fragility analysis of concrete gravity dams". ASCE Journal of Structural Engineering, 46: 04020121. https://doi.org/10.1061/(ASCE)ST.1943-541X.0002629

28 Murphy KP (2012). Machine Learning a Probabilistic Perspective. Cambridge, MA: MIT Press.

29 Segura RL, Bernier C, Monteiro R and Paultre P (2018). "On the seismic fragility assessment of concrete gravity dams in eastern Canada". Earthquake Spectra, 35(1):211231. https://doi.org/10.1193/012418EQS024M

30 Westberg M and Johansson F (2016). "Probabilistic Model Code for Concrete Dams". Rapport Technique 2016:292, Energiforsk.

31 Ghanaat Y, Patev RC and Chudgar AK (2012). "Seismic fragility analysis of concrete gravity dams". 15th World Conference on Earthquake Engineering, Lisbon.

32 Proulx J and Paultre P (1997). "Experimental and numerical investigation of dam-reservoir-foundation interaction for a large gravity dam". Canadian Journal of Civil Engineering, 24: 90-105. https://doi.org/10.1139/196-086

33 Mills-Bria B, Koltuniuk R and Percell P (2013). "State-ofPractice for the Nonlinear Analysis of Concrete Dams". Technical Report, U.S Department of the interior Bureau of Reclamation. https://doi.org/10.1061/(ASCE)07339445(2007)133:12(1710) 
34 Padgett JE and DesRoches R (2007). "Sensitivity of seismic response and fragility to parameter uncertainty". Journal of Structural Engineering, 133: 1710-1718. https://doi.org/10.1061/(ASCE)07339445(2007)133:12(1710)

35 Natural Resources Canada, NRC (2015). Simplified Seismic Hazard Map for Canada. http://www.earthquakescanada.nrcan.gc.ca/hazardalea/simphaz-eng.php. Visited on 2016-02-08

36 Atkinson G and Adams J (2013). "Ground motion prediction equations for application to the 2015 Canadian national seismic hazard maps". Canadian Journal of Civil Engineering, 40: 988-998.

https://doi.org/10.1139/cjce-2012-0544

37 Bradley BA (2010). "A generalized conditional intensity measure approach and holistic ground motion selection". Earthquake Engineering and Structural Dynamics, 56: 1321-1342. https://doi.org/10.1002/eqe.995

38 Hariri Ardebili M and Saouma V (2016). "Probabilistic seismic demand model and optimal intensity measure for concrete dams". Structural Safety, 59: 67-85. https://doi.org/10.1016/j.strusafe.2015.12.001

39 Baker JW (2011). "Conditional mean spectrum: Tool for ground-motion selection". Journal of Structural Engineering, 220: $1-8$. https://doi.org/10.1061/(ASCE)ST.1943-541X.0000215

40 Ancheta TD, Darragh RB, Stewart JP, Seyhan E, Silva WJ, Chiou KE, Brian SJ, Wooddell J, Graves RW, Kottke AR, Boore DM, Kishida T and Donahue JL (2013). "PEER NGA-West2 Database". Pacific Earthquake Engineering Research Center.
41 Goulet CA, Kishida T, Ancheta TD, Cramer CH, Darragh RB, Silva WJ, Hashash Y, Harmon J, Stewart JP, Wooddell KE and Youngs RR (2014). "PEER NGA-East Database". Pacific Earthquake Engineering Research Center.

42 Hurtado JE (2012). "Dimensionality reduction and visualization of structural reliability problems using polar features". Probabilistic Engineering Mechanics, 29: 16-31. https://doi.org/10.1016/j.probengmech.2011.12.004

43 Hasofer AM and Lind NC (1974). "Exact and invariant second-moment code format". Journal of Engineering Mechanics Division, 100: 111-121. https://doi.org/10.1061/JMCEA3.0001848

44 Bernier C, Padgett JE, Proulx J and Paultre P (2016). "Seismic fragility of concrete gravity dams with modelling parameter uncertainty and spatial variation". ASCE Journal of Structural Engineering, 142(5): 05015002. https://doi.org/10.1061/(ASCE)ST.1943-541X.0001441

45 Baker JW (2015). "Efficient analytical fragility function fitting using dynamic structural analysis". Earthquake Spectra, 31: 579-599. https://doi.org/10.1193/021113EQS025M

46 CDA (2007). "Dam Safety Guidelines, 2013 Revision". Canadian Dam Association (CDA), Edmonton, AB, Canada.

47 Vick SG (2002). "Degrees of Belief, Subjective Probability and Engineering Judgment". American Society of Civil Engineers, Reston, Virginia. $455 \mathrm{pp}$.

48 ASCE (2016). "Minimum Design Loads for Buildings and Other Structures". Technical Report, American Society of Civil Engineers, Reston, Virginia. 